\title{
A cross-sectional study of vitamin $D$ levels in a large cohort of patients with rheumatic diseases
}

\author{
Elena Nikiphorou ${ }^{1,2}$ • Jaakko Uksila ${ }^{3}$ Tuulikki Sokka ${ }^{1,4}$
}

Received: 7 August 2017 /Revised: 29 August 2017 / Accepted: 5 September 2017 / Published online: 7 November 2017

(C) The Author(s) 2017. This article is an open access publication

\begin{abstract}
The objective of this study is to examine 25hydroxyvitamin D [25(OH)D] (D-25) levels and associations with patient- and disease-related factors in rheumatic diseases. This is a register-based study of D-25 levels in adult patients seen at the Central Finland Hospital rheumatology clinic (January 2011-April 2015). Demographic, clinical, laboratory, and patient-reported outcomes (PROs) were collected as part of the normal infrastructure of the outpatient clinic and examined for their association with D-25 level. Statistical analysis included descriptive statistics and univariable and multivariable regression analyses adjusting for age and gender. D-25 was measured in 3203 patients (age range 1591 years, mean 54; 68\% female) with diagnoses including RA $(n=1386)$, unspecified arthralgia/myalgia $(n=413)$, and connective tissues diseases $(n=213)$. The overall D-25 mean (SD) level was 78 (31) and median (IQR) $75(55,97)$. At baseline, $17.8 \%$ had D-25 deficiency, and only $1.6 \%$ severe deficiency $(<25 \mathrm{nmol} / 1) ; 34 \% / 49 \%$ had sufficient/optimal D25 levels. Higher D-25 levels were associated with older age, lower BMI, and regular exercise (all $p<0.001$ ) among other
\end{abstract}

Elena Nikiphorou

enikiphorou@gmail.com

Tuulikki Sokka

tuulikki.sokka-isler@ksshp.fi

1 Rheumatology Department, Jyvaskylä Central Hospital, Jyväskylä, Finland

2 Academic Rheumatology Department, King's College London, London, UK

3 Laboratory, Jyvaskylä Central Hospital, Jyväskylä, Finland

4 Faculty of Health Sciences, University of Eastern Finland, Jyväskylä, Finland factors. In multivariable analyses, younger age, non-white background, higher BMI, smoking, less frequent exercise $(p<0.001)$, and first visit to the clinic $(p=0.033)$ remained significantly associated with D-25 deficiency. Among those with sub-optimal D-25 levels, $64 \%$ had improved to sufficient/optimal levels after a median (IQR) of $13(7.8,22)$ months. The proportion of patients with D-25 deficiency in this study was generally low. Older patients had considerably higher D-25 levels compared to younger patients. Lower physical exercise and higher BMI were associated with higher risk of deficiency. The study supports the benefit of strategies to help minimize the risk of D-25 deficiency.

Keywords 25-Hydroxyvitamin D · Autoimmune disease · Patient-reported outcomes $\cdot$ Rheumatoid arthritis $\cdot$ Vitamin D-25 deficiency

\section{Introduction}

Vitamin D (D-25) deficiency has represented a growing concern over the years, with a recognized higher risk at northern latitudes and in winter and spring seasons [1,2]. Reports on the re-emergence of rickets in Europe in the twenty-first century [3-6] have further strengthened concerns around the persistence of D-25 deficiency states and resulted in a number of mandatory food fortification and specific supplementation programs in various countries at risk. Epidemiological data suggest that D-25 deficiency may be a risk for the development of autoimmune, chronic diseases [2,7] including RA [8-10]. A meta-analysis showed a small reduction in all-cause mortality after D25 supplementation among older adults [11]. D-25 deficiency has been associated with non-specific musculoskeletal pain in acute rehabilitation unit patients [12]. 
Despite evidence supporting the pronounced effects of D25 deficiency in patients with known chronic musculoskeletal conditions, it does not always represent a priority treatment at all rheumatology clinics. There have been few studies examining the relationship between D-25 levels and RA disease outcomes such as functional status, physical exercise, and work status. A previous study [8] reported low D-25 levels to be an independent predictor of greater disability in patients with RA, but patient numbers were small and based on academic-setting rheumatology clinics.

The growing concerns around D-25 deficiency and impact on outcomes provided the rationale for this study. The objective was to analyze D-25 levels (25-hydroxyvitamin D $[25(\mathrm{OH}) \mathrm{D}])$ and its associations with patient and disease outcomes (clinical, laboratory, and patient-reported) using routine clinical care data at a large rheumatology outpatient clinic in central Finland.

\section{Materials and methods}

Study design and population This was a register-based, cross-sectional study which examined data from 3202 adult patients seen at the rheumatology clinic at Jyväskylä Central Hospital, Finland, between January 2011 and April 2015. Jyväskylä Central Hospital is the only rheumatology specialty unit in the Central Finland Health Care District serving a population of over a quarter of a million (5\% of the Finnish population) in Central Finland District, which is located between the latitudes of 61 and $63 \mathrm{~N}$. All new adult patients with suspected rheumatic diseases are referred to this center for diagnosis and management and those confirmed with rheumatic disease have regular follow-ups in outpatient and daycare units [13]. For over 20 years and throughout the period of this study, calcium and D-25 supplementation has been advised and prescribed routinely at the first clinic appointment, especially as many of these patients will be prescribed glucocorticoid treatment. This has been the policy of our clinic even before vitamin $\mathrm{D}$ testing was undertaken. If low vitamin $\mathrm{D}$ was identified in these patients, they were instructed to take additional supplementation. Furthermore, in Finland, an active national health promotion program regarding D-25 supplementation and fortification of milk and dairy products [14] further increases general public awareness. Measurement of D-25 levels has not been a routine practice in health care or in rheumatology clinics until it was implemented gradually since January 2011 at the rheumatology unit.

Data source Patients had their demographic, laboratory, clinical, and self-reported data collected as part of the normal infrastructure of the outpatient clinic using the electronic monitoring tool GoTreatIT [15]. Variables examined for are shown in Table 1.
Table 1 Description of variables extracted from GoTreatIT monitoring system and used in the analysis

\begin{tabular}{|c|c|}
\hline Variable & Description \\
\hline \multicolumn{2}{|l|}{ Demographic features } \\
\hline Age & Age at disease onset \\
\hline Gender & Male vs female \\
\hline Ethnic origin & White vs non-white \\
\hline Body mass index & $\begin{array}{l}\text { Self-reported weight in kilograms divided by the } \\
\text { square of height in meters }\end{array}$ \\
\hline Smoking & Current smoking vs non-smoking \\
\hline Education & Length of education in years \\
\hline \multicolumn{2}{|l|}{ Disease characteristics } \\
\hline Diagnosis & $\begin{array}{l}\text { Formal rheumatological diagnosis given by } \\
\text { physician }\end{array}$ \\
\hline Disease duration & $\begin{array}{l}\text { Calculated from clinical diagnosis to visit date } \\
\text { (in years) }\end{array}$ \\
\hline \multicolumn{2}{|c|}{ Patient-reported outcomes } \\
\hline HAQ & $\begin{array}{l}\text { Health Assessment Questionnaire, range 0-3; } \\
\text { higher scores imply more disability }\end{array}$ \\
\hline Pain & Pain on $0-100 \mathrm{~mm}$ Visual Analogue Scale (VAS) \\
\hline Patient global & $\begin{array}{l}\text { Patient assessment of global health on } 0-100 \mathrm{~mm} \\
\text { VAS }\end{array}$ \\
\hline $\begin{array}{l}\text { Patient disease } \\
\text { activity }\end{array}$ & $\begin{array}{l}\text { Patient assessment of disease activity on } \\
0-100 \mathrm{~mm} \text { VAS }\end{array}$ \\
\hline $\begin{array}{l}\text { Early morning } \\
\text { stiffness }\end{array}$ & Recorded in minutes \\
\hline Fatigue & Fatigue on $0-100$ VAS \\
\hline Physical exercise & $\begin{array}{l}\text { Self-reported engagement in physical activity (>half } \\
\text { hour/day with sweating, increased frequency in } \\
\text { breathing) categorized as follows: }>=3 \text { times/ } \\
\text { week; } 1-2 \text { times/week; } 1-2 \text { times/month; } \\
\text { none - categorized for analyses as: regular exer- } \\
\text { cise }>=3 \text { times/week vs irregular/no exercise }\end{array}$ \\
\hline \multicolumn{2}{|l|}{ Laboratory variables } \\
\hline ESR & Erythrocyte sedimentation rate \\
\hline $\begin{array}{l}\text { 25-Hydroxyvitamin } \\
\text { D [25(OH)D }]\end{array}$ & Serum vitamin $\mathrm{D}$ level ${ }^{\mathrm{a}}$ \\
\hline Crea & Creatinine \\
\hline $\mathrm{Hb}$ & Hemoglobin \\
\hline ALT & Alanine transaminase \\
\hline
\end{tabular}

${ }^{\mathrm{a}}$ See separate section in main document

\section{Serum vitamin D [25(OH)D] measurements}

Through the observation period, serum $25(\mathrm{OH}) \mathrm{D}$ concentrations were determined using automated competitive electrochemiluminescence binding assay (ref. 05894913 190, Modular Analytics E170 analyzer; Roche) according to the manufacturer's instructions. Cutoff levels were defined in accordance with the Finnish Current Care Guidelines [16, 17]: $<25 \mathrm{nmol} / 1=$ severe deficiency; $<50 \mathrm{nmol} / 1=$ deficiency; 50 $75 \mathrm{nmol} / 1=$ sufficient $>75=$ optimal $;>375=$ toxic . 
Table 2 D-25 levels (nmol/1) by diagnosis group and patient characteristics

\begin{tabular}{|c|c|c|c|c|c|c|}
\hline Diagnosis group & $\begin{array}{l}\text { Total } \\
n\end{array}$ & $\begin{array}{l}\text { Mean } \\
\text { age }\end{array}$ & $\begin{array}{l}\text { Female } \\
(\%)\end{array}$ & $\begin{array}{l}\text { Mean (SD) D- } \\
25 \text { level }\end{array}$ & $\begin{array}{l}\text { Median (IQR) D- } \\
25 \text { level }\end{array}$ & $\begin{array}{l}\% \text { less than } \\
50 \mathrm{nmol} / 1\end{array}$ \\
\hline Rheumatoid arthritis & 1386 & 61 & 70 & $81(31)$ & $78(58,101)$ & 15.4 \\
\hline $\begin{array}{l}\text { Arthralgia/myalgia } \\
\text { (non-specific) }\end{array}$ & 413 & 44 & 74 & $71(27)$ & $71(50,87)$ & 23.7 \\
\hline $\begin{array}{l}\text { Undifferentiated } \\
\text { arthritis }\end{array}$ & 216 & 47 & 63 & $74(28)$ & $72(53,91)$ & 19.4 \\
\hline $\begin{array}{l}\text { Ankylosing } \\
\text { spondylitis (axial) }\end{array}$ & 192 & 44 & 43 & $76(34)$ & $71(55,93)$ & 19.3 \\
\hline Vasculitis & 164 & 66 & 65 & $86(30)$ & $82(62,108)$ & 9.1 \\
\hline Psoriatic arthritis & 138 & 52 & 40 & $72(28)$ & $70(52,90)$ & 21.0 \\
\hline $\begin{array}{l}\text { Juvenile idiopathic } \\
\text { arthritis }\end{array}$ & 122 & 31 & 71 & $74(31)$ & $68(50,99)$ & 23.8 \\
\hline $\begin{array}{l}\text { Connective tissue } \\
\text { diseases }\end{array}$ & 213 & 53 & 85 & $82(32)$ & $80(60,98)$ & 14.6 \\
\hline Osteoarthritis & 96 & 64 & 83 & $76(29)$ & $76(55,93)$ & 18.8 \\
\hline Fibromyalgia & 67 & 49 & 87 & $74(32)$ & $67(50,90)$ & 23.9 \\
\hline Crystal arthritis & 36 & 62 & 22 & $74(34)$ & $69(57,83)$ & 16.7 \\
\hline Back pain & 33 & 40 & 73 & $77(31)$ & $78(50,98)$ & 21.2 \\
\hline Sarcoidosis & 10 & 54 & 70 & $70(21)$ & $68(50,85)$ & 20 \\
\hline Unknown & 117 & 50 & 72 & $74(31)$ & $69(51,94)$ & 21.4 \\
\hline All patients & 3203 & 54 & 68 & $78(31)$ & $75(55,97)$ & 17.7 \\
\hline
\end{tabular}

\section{Statistical analysis}

Descriptive statistics including mean, standard deviation (SD), 95\% confidence intervals $(95 \% \mathrm{CI})$, median, and interquartile range (IQR) were used in the descriptive part of the analysis. Differences between groups were analyzed using the Student's $t$ test for continuous and chi-square test for categorical variables. Univariable and multivariable (adjusting for age and gender) regression analyses were used with D-25 examined as both a continuous and categorical variable, based on cutoffs indicating specific D-25 status (see above).

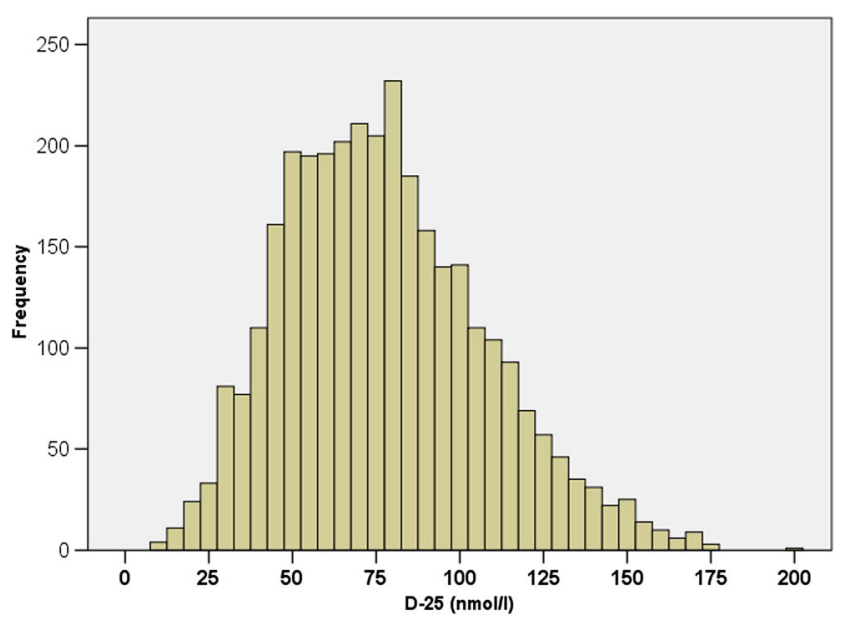

Fig. 1 Baseline vitamin D levels in 3203 patients in a rheumatology clinic

\section{Results}

\section{Patient characteristics}

A total of 3203 patients seen at Jyvaskyla Central Hospital rheumatology clinic between January 2011 and April 2015 had their D-25 levels measured. Patient age ranged from 15 to 91 years, mean age $54 ; 68 \%$ were female; $8.4 \%$ of the patient population was 15 to 25 years old $(4.1 \% 15$ to 20 years). All but 29 patients were North European origin. The majority of the patients $(43 \%)$ had rheumatoid arthritis (RA), non-specific arthralgia/myalgia (13\%), and undifferentiated arthritis (6.7\%). See Table 2 for patient characteristics.

\section{D-25 levels by diagnosis group}

The overall mean (SD) level of D-25 was 78 (31) nmol/l, and median (IQR) 75 (55, 97). Overall, 17.8\% had D-25 deficiency of $<50 \mathrm{nmol} / \mathrm{l}$, with only a very small proportion $(n=52$; $1.6 \%$ ) having severe deficiency of $<25 \mathrm{nmol} / 1$ (Fig. 1$)$. The majority $(n=1589 ; 49.6 \%)$ had optimal levels (D-25 $>75 \mathrm{nmol} / \mathrm{l})$ and $32.7 \%(n=1047)$ sufficient D-25 levels of $50-70 \mathrm{nmol} / 1$. Vitamin D levels by age and BMI are shown in Fig. 2. No patient had toxic levels of D-25. Table 2 summarizes D-25 levels and patient characteristics by diagnosis group. Overall, mean/median D-25 levels were higher in patients with vasculitis or connective tissue diseases (CTDs).

The highest proportion of patients with deficient D-25 levels was seen in the fibromyalgia, juvenile idiopathic arthritis (JIA), 
Fig. 2 a, b Vitamin D levels in 3203 patients in a rheumatology clinic, by age (a), age and BMI (b)

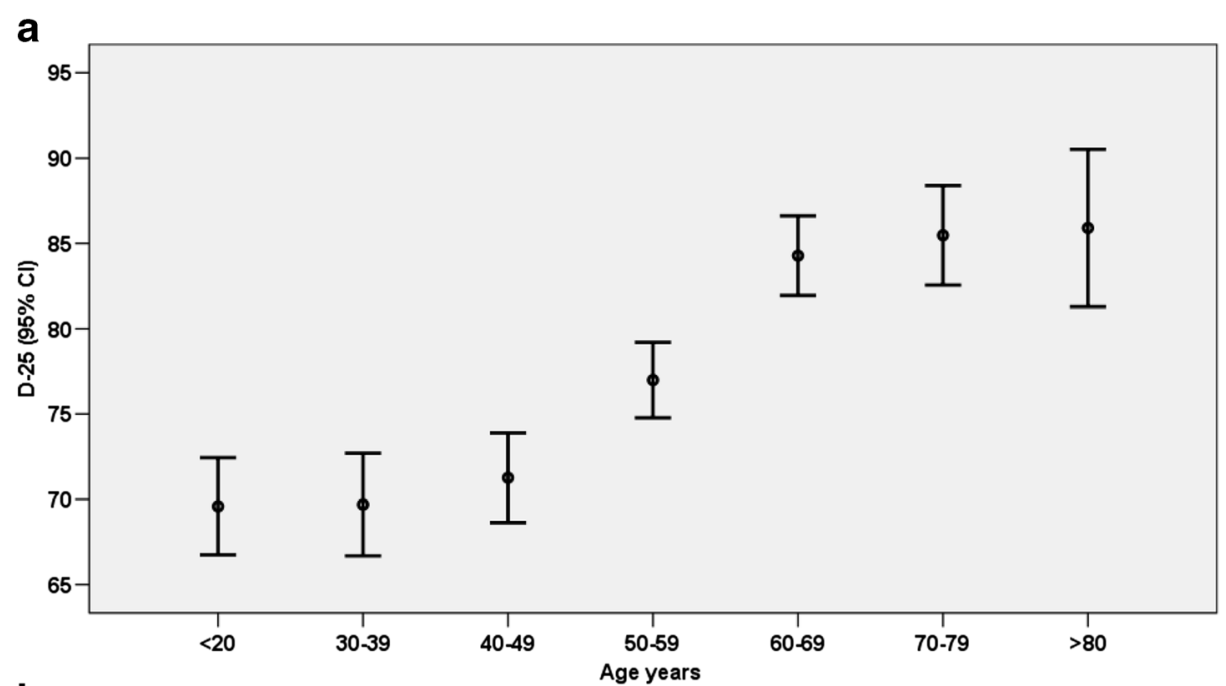

b

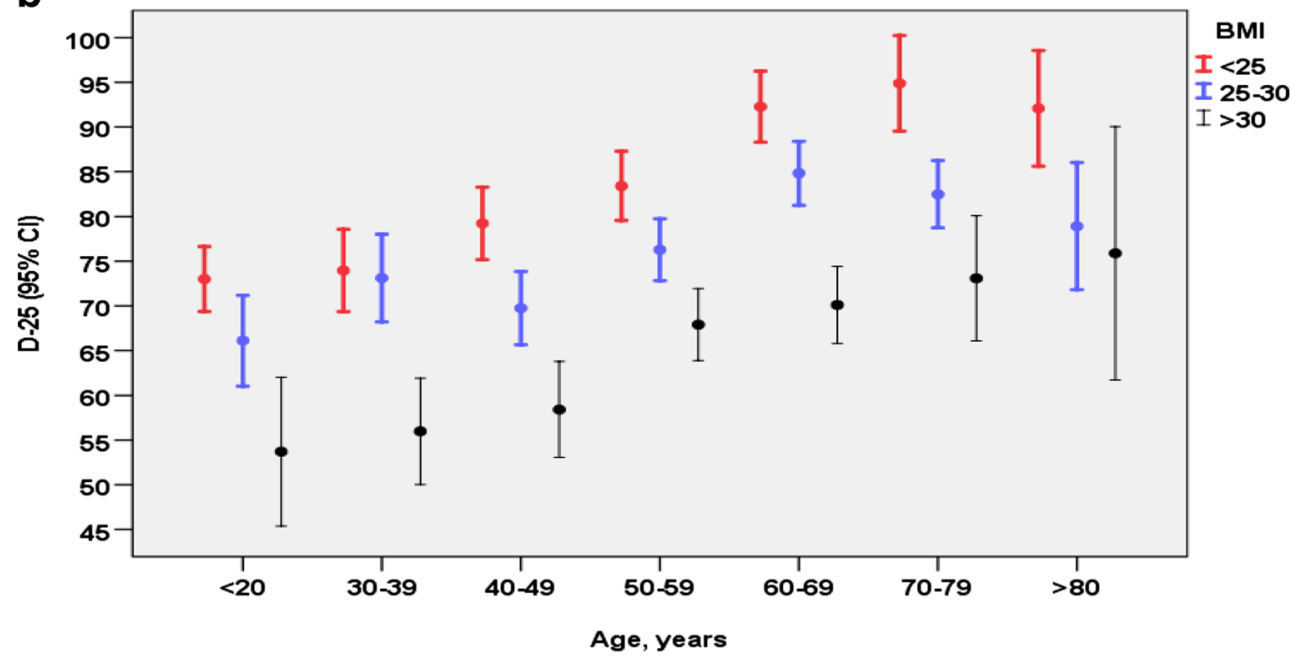

and non-specific arthralgia/myalgia diagnosis groups despite mean D-25 levels greater than $70 \mathrm{nmol} / \mathrm{l}$ in all these groups.

\section{Association between D-25 levels and patient characteristics}

D-25 levels were higher in patients seen at a follow-up visit in the clinic compared to patients who were seen at their first visit. Mean (95\% CI) D-25 levels were 80.8 (79.3 to 82.3) and 74.3 (72.8 to 75.8$),(p<0.001)$; respectively. Mean (95\% CI) D-25 levels were higher in women compared to men: 78.6 (77.3 to 79.8 ) vs 76.2 (74.3 to 78.1$)$; $(p=0.044)$, in non-smokers vs smokers: 78.6 (77.4 to 79.8$)$ vs 73.1 (70.3 to 75.8$)$; $(p<0.001)$, and in patients who reported regular physical exercise vs non-regular exercise: 82.0 (80.2 to 83.8) vs 75.3 (74.0 to 76.6$)$; $(p<0.001)$. Length of education did not have a significant association with vitamin D-25 levels.

D-25 levels increased by age (Fig. 3a). Lower BMI was associated with higher D-25 levels across all age groups (Fig. 3b).
Among 29 patients with darker skin, 20 (69\%) had D-25 deficiency, while the equivalent figure was $17 \%$ among 3174 patients with Northern European origin.

\section{Correlation between D-25 level, laboratory tests, and PROs}

Age rather than the D-25 level was associated with ESR, CRP, hemoglobin, ALT, and serum creatinine levels (Fig. 3a-e).

None of the patient-reported outcomes (PROs) correlated significantly with D-25 levels such as HAQ, pain, patient global score, and fatigue (data not shown).

\section{Multivariable analysis of associates of low D-25}

In multivariable analysis, younger age $(p<0.001)$, higher BMI $(p<0.001)$, and lack of regular exercise $(p=0.001)$ remained significant for the risk of D-25 deficiency $<50$. Patients of non-white background were 7.5 times (up to 17 times) more likely to be D-25 deficient compared to those of 
a

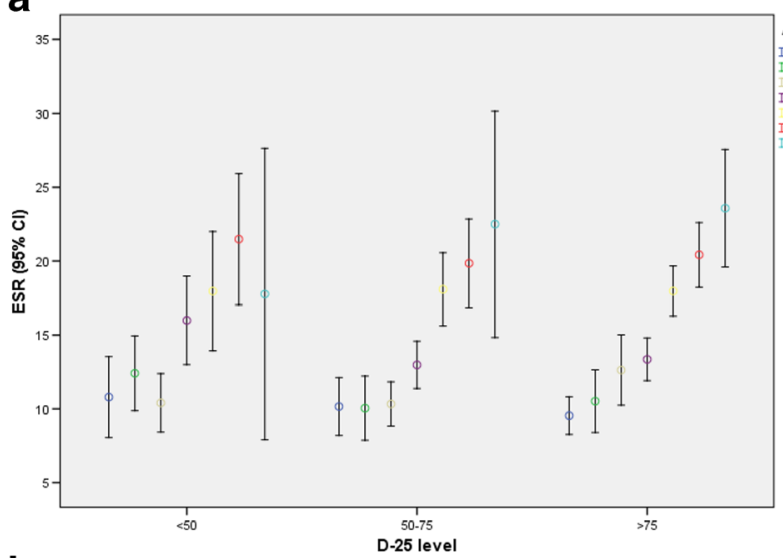

b

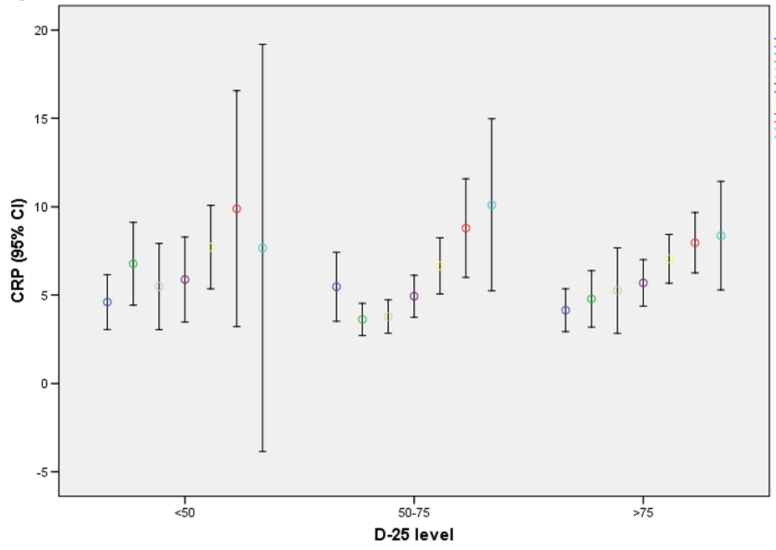

C

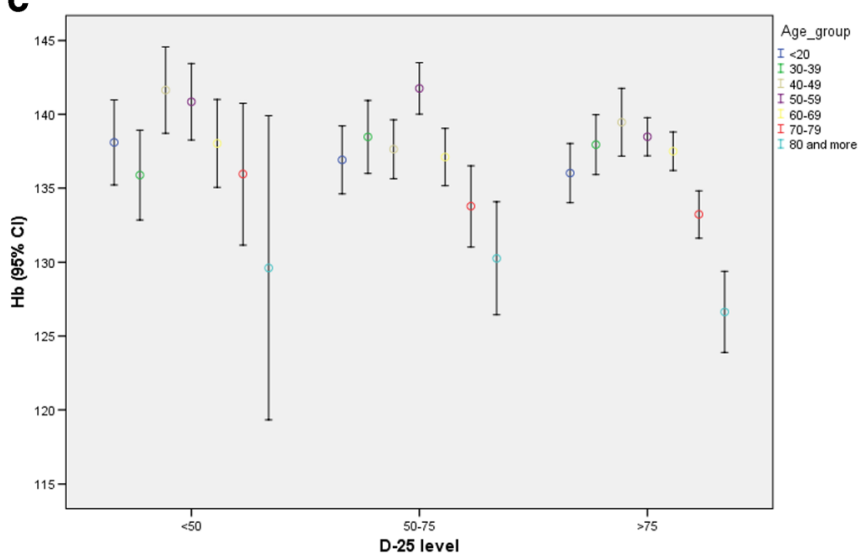

Fig. 3 a-e Laboratory measures in relation to vitamin D-25 level and age

white background $(p<0.001)$. Smoking was associated with higher risk of D-25 deficiency ( $p=0.001$ ). Also, first visit to the clinic $(p=0.033)$ remained significant for the risk of D-25 deficiency (Table 3).

\section{Vitamin D-25 levels at follow-up}

Roughly one third of the patients had D-25 re-measured after a median (IQR) of $13(7.8,22)$ months. Among those who had d

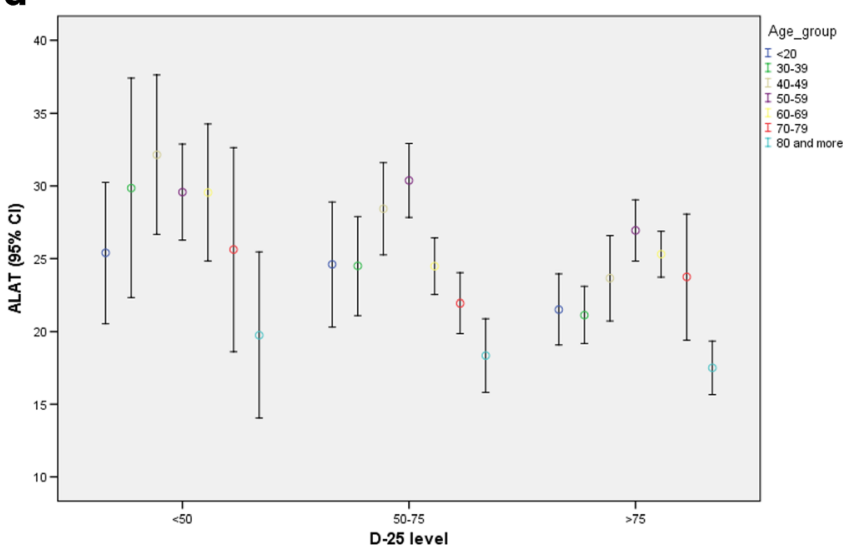

e

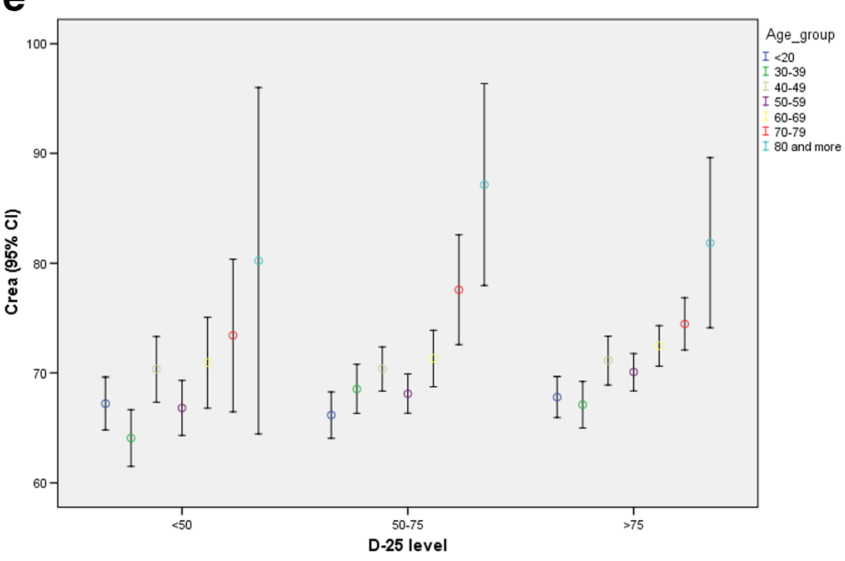

sub-optimal values for D-25, 64\% had improved to sufficient or optimal levels (data not shown).

\section{Discussion}

This cross-sectional study of D-25 levels in patients with rheumatic diseases in central Finland indicates that the great majority had optimal levels. This is particularly relevant in current times as there have been several reports to 
Table 3 Multivariable analysis model of factors associated with low D-25

\begin{tabular}{lrrrrr}
\hline & $B$ coeff & $p$ value & Exp $(B)$ & \multicolumn{2}{c}{ 95\% CI for exp. $(B)$} \\
\hline Sex, female vs male & & & & Lower & Upper \\
Age & -0.083 & 0.428 & 0.920 & 0.750 & 1.130 \\
Race, non-white vs white & -0.026 & $<0.001$ & 0.974 & 0.969 & 0.980 \\
Smoking now vs non-smoking & 2.015 & $<0.001$ & 7.503 & 3.298 & 17.067 \\
BMI & 0.405 & 0.001 & 1.499 & 1.171 & 1.919 \\
Physical exercise, regular vs not-regular & -0.072 & $<0.001$ & 1.075 & 1.057 & 1.093 \\
Visit, return visit to clinic vs first & -0.213 & 0.001 & 0.703 & 0.569 & 0.869 \\
Constant & -2.001 & $<0.001$ & 0.135 & & 0.683 \\
\hline
\end{tabular}

date demonstrating lower D-25 levels in Nordic countries and increasing prevalence of rickets, cancer, diabetes, obesity, and morbidities may be associated with D-25 inadequacy [17]. In our study, we observed an increasing D-25 level with increasing age; in other words, older patients had higher D-25 levels than younger patients. This is a paradox considering that with older age, one would expect lower D-25 intake, intestinal absorption, and capacity to convert vitamin D to its active form in the kidneys and skin. A possible explanation for this observation could be precisely the active D-25 screening and supplementation strategies employed both at the clinic but also at national level, minimizing the risk of D-25 deficiency.

Only $17.8 \%$ of patients had D-25 deficiency, and in only less than $2 \%$ this was severe. Based on D-25 levels by diagnosis group, mean levels ranged between 70 and 86 (sufficient/optimal range). Patients with vasculitis and CTDs were found to have the highest levels of mean and median D-25 levels across all diagnosis groups, which could reflect more targeted supplementation in patients at risk or with known autoimmune diseases such as systemic lupus erythematosus and with potentially higher glucocorticoid requirements $[18,19]$.

The role of D-25 in calcium homeostasis, bone mineralization, and preservation of bone health is well established, as is the need for adequate D-25 levels for general musculoskeletal health. Therefore, patients with rheumatic diseases represent a high-risk group. The analysis of D-25 levels by diagnosis group in the study could help in the identification of vulnerable patient groups that should be more closely targeted. Diagnosis groups with the highest proportion (around 1 in 5) of patients having deficiency were the JIA, fibromyalgia, and the non-specific arthralgia/myalgia groups. For the latter two, lower D-25 levels could have a causal role and could reflect a particularly vulnerable group of patients who should be more closely targeted. With regard to JIA patients, one could speculate that their younger age (mean age 31 ) could predispose to lower health awareness and less engagement in healthy lifestyle, dietary habits, and supplementation intake despite recommendations. This finding is supported by the multivariable regression analysis where younger age was a significant independent predictor of D-25 deficiency. However, only $8.4 \%$ of the patient population was below the age of 25 ; the prevalence of D-25 deficiency may be much higher in young people in the general population.

The study identified non-white ethnic background, less physical exercise, smoking, and higher BMI as further independent predictors of D-25 deficiency, suggesting a possible target group of patients. These variables could represent surrogates of a healthy lifestyle. Women were also found to have higher levels of D-25 compared to men, supporting previous data [20]. This could suggest gender-related pathophysiological mechanisms at play, or simply differences in health and dietary perceptions and supplement intake.

The finding of generally higher D-25 levels in this study contradicts findings from previous studies where D-25 deficiency, especially in countries at northern latitudes, has been a major problem [2-6]. We can speculate that the local clinic policy on the background of mandatory food fortification (e.g., of liquid milk and dairy products) and appropriate supplementation programs along with health campaigns since the early 2000s [14] are at least partly accountable for the results. Improvements in D-25 states at a national level in Finland have been suggested in the latest dietary survey FINDIET in 2012 [21], where Finnish adults met the D-25 recommendations on average, except in older women. The example of Finland raises hope that such programs and interventions at a national level could positively influence population outcomes, as seen with the example of D-25.

The finding of lower education correlating significantly with higher D-25 levels was interesting as one would expect the two to be in the same direction. However, this could in fact highlight that despite lower individual education levels, nationwide health promotion programs and local supplementation policies can be equally effective for this purpose. Another explanation could be that patients with lower education may have more manual-labor occupations and hence more time spent outdoors and higher sunlight exposure. The study 
showed that in patients whose care was maintained in the clinic as follow-up visits, compared to first time visitors, had higher D-25 levels and this could indirectly suggest more opportunity for education.

The large patient numbers and examination of demographic, clinical, and patient-reported variables common across several disease groups represent strengths of the study. Limitations include its observational, cross-sectional nature which makes associations between variables challenging to interpret. The cross-sectional analysis meant that not all D-25 measurements were at baseline (i.e., first patient review in clinic) but some were at different time points, which is a further limitation of the study. However, this way it was possible to examine for differences in D-25 levels based on follow-up time. Furthermore, the examination of associations between D-25 levels and specific outcomes at single time points is a possible source of bias and could have prevented real effects and associations from being seen.

This study provides evidence that D-25 national policies and health promotion campaigns along with local/ departmental polices for the most vulnerable population groups can be effective. Such strategies may be more effective in some populations compared to other and it is important that national, cultural, and dietary habits are taken into account [14]. The study raises hope on a health issue that has represented a growing concern over time, demonstrating that D-25 deficiency states can be actively prevented. We further conclude that there is value in testing D-25 levels in patients with rheumatic diseases and especially those at high risk.

Funding This work was supported by a EULAR Scientific Training bursary awarded to EN.

\section{Compliance with ethical standards}

Disclosures None.

Ethical approval Non-interventional, register-based study (responsible institution: The Health Care District, Finland) conducted according to standard national and local policy specifications (for further information please see: https://rekisteritutkimusen.wordpress.com/). Data collection was performed as part of usual clinical monitoring with no extra data collected.

Open Access This article is distributed under the terms of the Creative Commons Attribution 4.0 International License (http:// creativecommons.org/licenses/by/4.0/), which permits unrestricted use, distribution, and reproduction in any medium, provided you give appropriate credit to the original author(s) and the source, provide a link to the Creative Commons license, and indicate if changes were made.

\section{References}

1. Cutolo M, Otsa K, Laas K et al (2006) Circannual vitamin D serum levels and disease activity in rheumatoid arthritis: Northern versus
Southern Europe. Clin Exp Rheumatol 24(6):702-704. http://www. ncbi.nlm.nih.gov/pubmed/17207389

2. Holick MF (2004) Sunlight and vitamin D for bone health and prevention of autoimmune diseases, cancers, and cardiovascular disease. Am J Clin Nutr 80(6 Suppl):1678S-1688S. http://www. ncbi.nlm.nih.gov/pubmed/15585788

3. Hyppönen E, Power C (2007) Hypovitaminosis D in British adults at age $45 \mathrm{y}$ : nationwide cohort study of dietary and lifestyle predictors. Am J Clin Nutr 85(3):860-868. http://www.ncbi.nlm.nih.gov/ pubmed/17344510

4. Callaghan AL, Moy RJD, Booth IW, Debelle G, Shaw NJ (2006) Incidence of symptomatic vitamin D deficiency Arch Dis Child 91(7):606-607. http://www.pubmedcentral.nih.gov/articlerender. fcgi?artid $=2082851 \&$ tool $=$ pmcentrez\&rendertype $=$ abstract

5. Ahmed SF, Franey C, McDevitt Het al (2011) Recent trends and clinical features of childhood vitamin D deficiency presenting to a children's hospital in Glasgow. Arch Dis Child 96(7):694-696. http://www.ncbi.nlm.nih.gov/pubmed/20584848

6. Beck-Nielsen SS, Brock-Jacobsen B, Gram J, Brixen K, Jensen TK (2009) Incidence and prevalence of nutritional and hereditary rickets in southern Denmark. Eur J Endocrinol 160(3):491-497. http:// www.ncbi.nlm.nih.gov/pubmed/19095780

7. Holick MF (2004) Vitamin D: importance in the prevention of cancers, type 1 diabetes, heart disease, and osteoporosis. Am J Clin Nutr 79(3):362-371. http://www.ncbi.nlm.nih.gov/pubmed/ 14985208

8. Haque UJ, Bartlett SJ (2010) Relationships among vitamin D, disease activity, pain and disability in rheumatoid arthritis. Clin Exp Rheumatol 28(5):745-747. http://www.ncbi.nlm.nih.gov/pubmed/ 20883640

9. Oelzner P, Müller A, Deschner Fet al (1998) Relationship between disease activity and serum levels of vitamin D metabolites and PTH in rheumatoid arthritis. Calcif Tissue Int 62(3):193-198. http:// www.ncbi.nlm.nih.gov/pubmed/9501950

10. Kröger H, Penttilä IM, Alhava EM (1993) Low serum vitamin D metabolites in women with rheumatoid arthritis. Scand J Rheumatol 22(4):172-177. http://www.ncbi.nlm.nih.gov/pubmed/8356409

11. Chowdhury R, Kunutsor S, Vitezova A et al 2014 Vitamin D and risk of cause specific death: systematic review and meta-analysis of observational cohort and randomised intervention studies. BMJ 348:g1903. http://www.pubmedcentral.nih.gov/articlerender.fcgi? artid $=3972416 \&$ tool $=$ pmcentrez\&rendertype $=$ abstract

12. Matossian-Motley DL, Drake DA, Samimi JS, Camargo CA, Quraishi SA (2014) Association between serum 25(OH)D level and nonspecific musculoskeletal pain in acute rehabilitation unit patients. JPEN J Parenter Enteral Nutr 40(3):367-373. http://www. ncbi.nlm.nih.gov/pubmed/25316682

13. Vare P, Nikiphorou E, Hannonen P, Sokka T (2016) Delivering a one-stop, integrated, and patient-centered service for patients with rheumatic diseases. SAGE Open Med 4(0):2050312116654404. http://www.ncbi.nlm.nih.gov/pubmed/27437101

14. Spiro A, Buttriss JL (2014) Vitamin D: an overview of vitamin D status and intake in Europe. Nutr Bull 39(4): 322-350. http://www.pubmedcentral.nih.gov/articlerender. fcgi $?$ artid $=4288313 \&$ tool $=$ pmcentrez $\&$ rendertype $=$ abstract

15. Sokka T, Haugeberg G, Pincus T (2007) Assessment of quality of rheumatoid arthritis care requires joint count and/or patient questionnaire data not found in a usual medical record: examples from studies of premature mortality, changes in clinical status between 1985 and 2000, and a QUEST-RA global perspective. Clin Exp Rheumatol 25(6 Suppl 47):86-97. http://www.ncbi.nlm.nih.gov/ pubmed/18021512

16. Current care guidelines: the Finnish Medical Society. http://www. kaypahoito.fi/web/english/home

17. Sharma S, Barr AB, Macdonald HM, Sheehy T, Novotny R, Corriveau A (2011) Vitamin D deficiency and disease risk among 
aboriginal Arctic populations. Nutr Rev 69(8):468-478. http:// www.ncbi.nlm.nih.gov/pubmed/21790613

18. Kauppinen-Mäkelin R, Tähtelä R, Löyttyniemi E, Kärkkäinen J, Välimäki MJ (2001) A high prevalence of hypovitaminosis D in Finnish medical in- and outpatients. J Intern Med 249(6):559-563. http://www.ncbi.nlm.nih.gov/ pubmed/11422663
19. Barnes TC, Bucknall RC Vitamin D deficiency in a patient with systemic lupus erythematosus. Rheumatology (Oxford) 43(3):393394. http://www.ncbi.nlm.nih.gov/pubmed/14963211

20. Miettinen M, Kinnunen L, Keinänen-Kiukanniemi S (2013) Prevalence of vitamin D insufficiency in Finnish adult population. Suom Lääkäril 4:29-33. [in Finnish]

21. Helldán A, Raulio S, Kosola M, Tapanainen H, Ovaskainen M-L, Virtanen S (2013). Finravinto 2012 -tutkimus - The National FINDIET 2012 Survey. http://www.julkari.fi/handle/10024/110839 